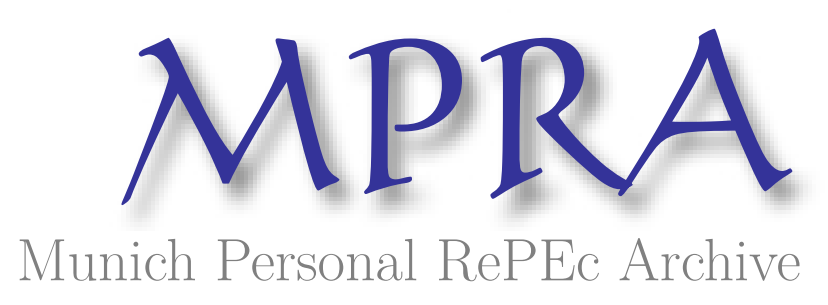

\title{
Public Policy Against Political Frictions
}

\author{
Grechyna, Daryna
}

January 2017

Online at https://mpra.ub.uni-muenchen.de/76396/

MPRA Paper No. 76396, posted 30 Jan 2017 09:56 UTC 


\title{
Public Policy Against Political Frictions
}

\author{
Daryna Grechyna*
}

January 2017

\begin{abstract}
Recent research has demonstrated that political distortions can aggravate macroeconomic volatility. The aim of this paper is to analyze a fiscal policy institution capable of reducing the influence of such distortions on politically-driven fluctuations. We introduce the distinction between mandatory and discretionary public spending in the political model of optimal fiscal policy. We show that the different legislative nature of these components of government spending leads to a divergent impact of mandatory and discretionary spending on macroeconomic volatility. Increasing the fraction of mandatory spending in total government spending reduces the politicallydriven volatility of income taxes, total government spending, consumption, labor, and output. Increasing the fraction of discretionary spending has the opposite effect. Our findings are supported by empirical evidence.
\end{abstract}

Keywords: optimal fiscal policy, mandatory and discretionary public spending, political polarization, political turnover, macroeconomic volatility.

JEL Classification Numbers: E6, H1, H3, H4.

${ }^{*}$ Department of Economics, Middlesex University London, Business School, Hendon Campus, The Burroughs, London NW4 4BT, UK. Tel.: +44 (0)2084115000. E-mail: dgrechna@gmail.com. 


\section{Introduction}

Government policy plays a significant role in a country's economic performance. One of the barriers that prevents government policy from targeting and achieving socially desirable outcomes is its political nature. Frictions in the form of political instability, polarization, and public rent-seeking may lead to fiscal policy being dictated by the interests of particular power groups rather than by economic considerations.

The aim of this paper is to consider and quantify the importance of a fiscal policy institution that is capable of reducing the influence of political frictions on fiscal policy outcomes. In particular, we introduce the distinction between mandatory and discretionary public spending in the political model of optimal fiscal policy. Mandatory spending is defined as expenditure that is governed by law, rather than by periodic appropriations (possible examples are health care and social security). Discretionary spending is defined as expenditure that is governed by annual or other periodic appropriations (possible examples are defense and public order spending). We show that the different legislative nature of these components of government spending leads to a divergent impact of mandatory and discretionary spending on macroeconomic outcomes. Increasing the fraction of mandatory spending in total government spending reduces the politically-driven volatility of income taxes, total government spending, consumption, labor, and output. Increasing the fraction of discretionary spending has the opposite effect.

The intuition behind these results is as follows. It has been shown elsewhere that alternating governments with different preferences over the size of public sector introduce fluctuations in macroeconomic variables (Azzimonti, 2011; Azzimonti and Talbert, 2014). The governments that prefer a larger public sector choose higher taxes to finance higher levels of government spending than the governments that prefer a smaller public sector. Political turnover leads to preference-driven fluctuations in taxes and government spending, which, in the case of distortionary taxes, affect household consumption, labor, and, eventually, the output. Introduction of mandatory spending, which is more rigid than discretionary spending, restricts the government's ability to select its preferred policy. This restriction leads to lower divergence between the fiscal variables set by alternating governments and, therefore, reduces the fluctuations caused by political frictions.

Our findings have important policy implications for both developing and developed economies. We show that introducing a legislative base for politically binding mandatory 
spending can reduce the impact of political frictions on macroeconomic volatility. This conclusion complements the general agreement in literature that stronger institutions are necessary for economic improvement in developing countries. We also show that in the economies with functioning mandatory spending, increasing its fraction given the size of public sector reduces politically-driven macroeconomic fluctuations. Thus, a more "rulesbased" fiscal policy can be beneficial for economic performance in developed countries where the fiscal institutions are already relatively strong.

The public policy inefficiencies resulting from political frictions have been widely discussed in previous literature. Persson and Tabellini (2000) provide a survey of some of the related studies. Political turnover combined with political disagreement about the size or the composition of public goods have been shown to lead to higher debt levels, high distortionary taxes, government overspending, and lower levels of investment and output (Persson and Svensson, 1989; Alesina and Tabellini, 1990; Battaglini and Coate, 2008; Yared, 2010; and Azzimonti, 2011). Ilzetski (2011), Tornell and Lane (1999), Alesina, Campante, and Tabellini (2008) and Woo (2009) use political frictions to explain procyclicality of fiscal policy in developing countries.

The role of fiscal policy in macroeconomic stability has also enjoyed significant attention in recent academic research. One of the important topics under discussion has been whether the public sector has a stabilizing or destabilizing effect on output, but the answer is ambiguous in general. As Fatás and Mihov (2006) point out, less discretion should reduce volatility, and less responsiveness of fiscal policy might amplify business cycles. Fiscal policy restrictions can reduce the ability of governments to react to business cycle fluctuations, but they can also limit the ability of politicians to use the fiscal policy to further their interests, leading to lower economic fluctuations. Fatás and Mihov (2006) find empirical support for the latter argument: fiscal restrictions, by reducing discretion in fiscal policy, can reduce macroeconomic volatility. Fatás and Mihov (2003) also find that institutional restrictions on governments that limit government discretion reduce output volatility.

Our paper discusses one of such institutional restrictions: mandatory public spending. Given that this type of spending is governed by formulas or criteria set forth in enacted law, it is more resistant to changes than discretionary spending which is governed by periodic appropriations. In this sense, mandatory spending should reduce politically-driven 
fluctuations. We must admit that there is another possibility: higher fraction of mandatory spending can also reduce the government ability to smooth out business cycle fluctuations. As we discuss in one of the sections of this paper, we indeed find that higher mandatory spending can lead to increased volatility from the exogenous technology shocks.

A number of studies analyze the role of political institutions in fiscal policy design and macroeconomic stability (see, for example, Fatás and Mihov, 2013; Fatás and Mihov, 2003; Acemoglu et al., 2003; and Klomp and de Haan, 2009). Their findings generally agree that weaker institutions increase economic volatility, possibly through their impacts on fiscal policy conduct.

Our study is closely related to Bowen, Chen, and Eraslan (2014), which models mandatory spending in a legislative bargaining framework and discusses its efficiency relative to discretionary spending. Similar to these authors, we consider an economy with political frictions in the form of political turnover and polarization and we assert that mandatory spending allows to achieve political compromise in the context of public good provision. Differently from these authors, in our model the output is endogenously determined, which allows us to analyze the consequences of mandatory spending for macroeconomic volatility.

Another related study to ours is Azzimonti and Talbert (2014), which discusses how political frictions can lead to economic fluctuations. The authors show that in an economy characterized by political disagreement about the size of government sector, political turnover leads to macroeconomic fluctuations even without any other sources of macroeconomic volatility. The authors suggest that the higher volatility characterizing developing countries, as compared to developed countries, can be at least partially explained by the higher political frictions that often exist in those countries. In our work, compared to Azzimonti and Talbert (2014), we add another dimension of fiscal policy, mandatory public spending, and show that it can mitigate the fluctuations caused by political frictions.

The paper is organized as follows. In Section 2, we provide empirical evidence on the existence of an association between macroeconomic volatility and the fraction of mandatory spending in total government spending. Section 3 presents and characterizes a simple model that combines political instability, political polarization, and optimal fiscal policy comprised of distortionary taxes and discretionary and mandatory public spending. Section 4 provides quantitative evaluation of the importance of mandatory spending for macroeconomic volatility using numerical simulations of the model. In Section 5 we discuss our 
several applications and extensions of our results. Section 6 concludes.

\section{The Data}

In this section we document the existence of an association between macroeconomic volatility and the fraction of mandatory spending in total government spending. Azzimonti and Talbert (2014) and Woo (2009) have shown that political/social polarization increases macroeconomic volatility. Our hypothesis is that this negative effect of polarization can be reduced by the constraint imposed by mandatory spending on the government in power.

Figure 1 shows three time series of interest for the U.S economy. The political polarization measure is taken from Poole and Rosenthal (2000), the mandatory spending as a fraction of total government outlays is from the Government Budget historical tables, and the output volatility is measured as the standard deviation of output growth over five-year rolling window periods. Both the political polarization and the mandatory spending increased significantly between 1960 and 2015, while the output volatility decreased over the same time period. At the same time, the share of total government spending in the GDP (not shown on the graph) did not change significantly during that time.

In the United States, mandatory spending refers to budget authority and ensuing outlays provided in laws other than appropriations acts, including annually appropriated entitlements. It is explicitly specified in the data and therefore is easy to identify. The main components of mandatory expenditures are social security and health expenditures (Medicare and Medicaid), with unemployment and other social benefits accounting for the remaining twenty percent. For other countries, there is generally no explicit definition that separates mandatory and discretionary government spending. We therefore consider public social and health expenditures as a proxy for mandatory spending in other economies.

Figure 2 presents a scatterplot of social expenditures as a fraction of total government expenditures and the output growth volatility for the OECD countries, both variables having been averaged over the period 1990-2015. We use the OECD Statistics data on public social expenditures, which include social benefits, health expenditures, unemployment, housing, and other social policy areas (Adema, Fron and Ladaique, 2011). The figure suggests that there is a negative association between the two variables in a cross section of developed (OECD) countries. 
Figure 1: Political polarization, mandatory spending, and output growth volatility in the U.S.

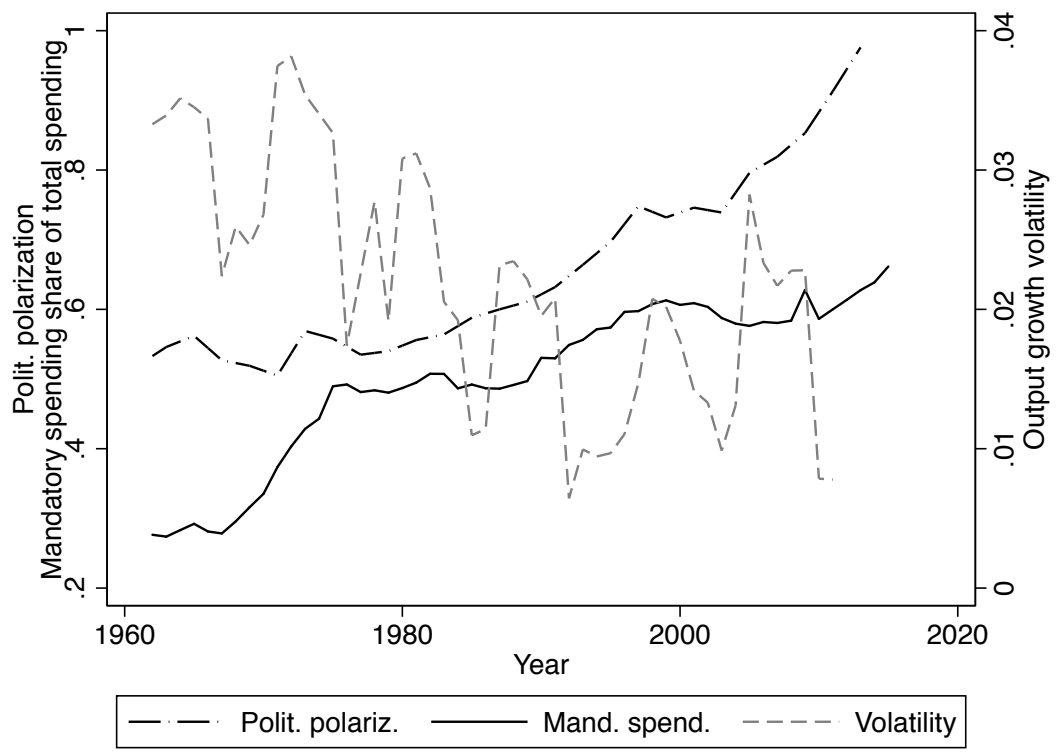

Data source: Historical Tables of the United States Government Budget; Poole and Rosenthal (original bi-annual time-series have been interpolated to annual data).

To evaluate the degree of association between social expenditures and macroeconomic volatility, we regress the measure of volatility (the standard deviation of the output growth, evaluated over 1990-2015) on the social expenditures fraction of government spending (averages over the available data between 1990 and 2015) and on a proxy of political polarization. ${ }^{1}$ We include the average level of output growth, to control for the fact that growth volatility is not scale-independent. Given that the cross-country data on political polarization is scarce and that political polarization can be endogenous with respect to macroeconomic volatility, we use ethnolinguistic polarization considered as one of the fundamental determinant of social and political polarization (see Esteban and Ray, 2011). The results of cross-section OLS regressions for OECD economies are presented in Table 1, Columns 1 and 2. The results suggest that for the OECD economies, there is no significant impact of social polarization on economic volatility; at the same time, a higher share of social expenses in total government expenditures is associated with lower economic volatility.

\footnotetext{
${ }^{1}$ We also tried to include the political instability measure from the World Bank, but it appeared to be insignificant in all the regressions. As will be seen in the model presented in the next section, the impact of mandatory spending on volatility is determined by political polarization rather than political instability, although some political instability (turnover) is necessary to generate fluctuations in the economy.
} 
Figure 2: Output growth volatility and public social expenditures in the OECD.

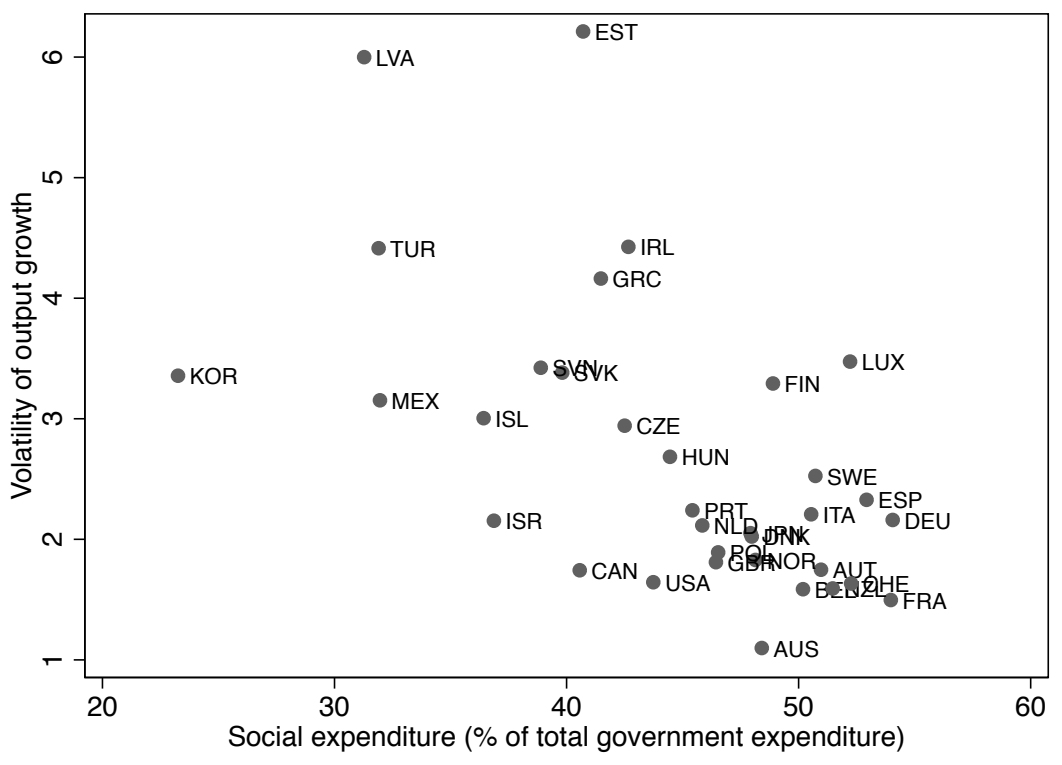

Data source: The OECD Statistics.

We further look at a sample of 159 countries characterized by different development levels. We use the sum of public expenditures on health and education (the only two "social" types of public expenditures available for a large set of countries) as a proxy of mandatory public spending. Table 1 Column 3 presents the results for the cross-section of countries with output growth rate volatility calculated over 1995-2015, and social expenditures averaged over 1995-2015. Ethnolinguistic polarization is used as a proxy for political polarization. Compared to the sample consisting only of OECD economies, the estimation on the broader set of countries delivers a positive and significant coefficient of polarization. The coefficient of social expenditures remains negative and significant.

The estimates for the OECD countries suggest that polarization is not a significant determinant of macroeconomic volatility in these countries. This may be due to the fact that OECD countries are relatively developed economies where the institutions are strong enough to eliminate the negative effect of political frictions. The same cannot be said about the world in general, given the significance of polarization coefficients for a broader set of countries.

Our hypothesis is that the institutional constraints that impose higher mandatory spending can reduce the effect of polarization on volatility. We add the interaction between the polarization measure and the mandatory spending measure (both variables centered 
Table 1: Cross-section estimates of the association between social spending and macroeconomic volatility.

\begin{tabular}{|c|c|c|c|}
\hline VARIABLES & (1) & $(2)$ & (3) \\
\hline \multirow[t]{2}{*}{ Polarization } & 0.585 & $1.026^{*}$ & $2.497^{*}$ \\
\hline & $(0.809)$ & $(0.565)$ & $(1.306)$ \\
\hline \multirow[t]{2}{*}{ Social Exp. } & $-0.0621^{* *}$ & $-0.0545^{* *}$ & $-0.168^{* *}$ \\
\hline & $(0.0278)$ & $(0.0216)$ & $(0.0662)$ \\
\hline \multirow[t]{2}{*}{ Polarization $\times$ Social Exp. } & -0.0978 & -0.101 & 0.329 \\
\hline & $(0.0667)$ & $(0.0811)$ & $(0.259)$ \\
\hline \multirow[t]{2}{*}{$1(\operatorname{Exp}>\operatorname{Avg})$} & & & $0.854^{*}$ \\
\hline & & & $(0.452)$ \\
\hline \multirow[t]{2}{*}{$1(\operatorname{Exp}>$ Avg $) \times$ Polarization } & & & 0.329 \\
\hline & & & $(1.756)$ \\
\hline \multirow[t]{2}{*}{ 1(Exp $>$ Avg $) \times$ Social Exp. } & & & 0.0673 \\
\hline & & & $(0.0815)$ \\
\hline \multirow[t]{2}{*}{ 1(Exp $>$ Avg $) \times$ Polariz. $\times$ Social Exp } & & & $-0.745^{* *}$ \\
\hline & & & $(0.308)$ \\
\hline \multirow[t]{2}{*}{ Avg. Growth Rate } & $0.520^{* *}$ & 0.154 & 0.139 \\
\hline & $(0.214)$ & $(0.106)$ & $(0.0998)$ \\
\hline \multirow[t]{2}{*}{ Constant } & $1.733^{* * *}$ & $3.096^{* * *}$ & $2.577^{* * *}$ \\
\hline & $(0.467)$ & $(0.269)$ & $(0.440)$ \\
\hline Observations & 34 & 159 & 159 \\
\hline R-squared & 0.560 & 0.092 & 0.138 \\
\hline
\end{tabular}

The dependent variable is the standard deviation (over 1990-2015) of real GDP per capita growth rate. Avg. Growth Rate denotes the average growth rate of real GDP per capita. 1(Exp $>$ Avg) denotes a dummy that takes value one if the average social expenditures share of total government spending is greater than the average across all the countries in the sample. All the variables except of Avg. Growth Rate are centered around their mean. Estimation method: OLS. Robust errors in parenthesis; ***, **, and $*$ denote significance at the $1 \%, 5 \%$, and $10 \%$ significance level, respectively.

around their means) to evaluate this hypothesis. The interaction terms are not significant in Columns 1-2 of Table 1. For OECD economies, the insignificance of the interaction term may be due to the insignificance of the polarization itself. For the broader set of countries, considered in Column 2, the insignificance of the interaction might be due to the fact that the mandatory spending fraction is not large enough to reduce the impact of political fric- 
tions. We add the interactions of all the variables with a dummy which takes value one if the fraction of social expenses in total government spending in a particular country is above the average value of this variable in the sample. This separates the estimates for countries with relatively low and high social expenditures. The results are presented in Column 3 of Table 1 . The polarization coefficient remains positive and significant, and its interaction with social expenditures is negative and significant for the countries that have social expenditures above the average over all the countries in the sample. For such countries, higher social expenditures reduce the contribution of polarization to macroeconomic volatility.

Overall, the data suggests that there is a negative association between mandatory spending and macroeconomic volatility. In the next section, we construct a model that shows how this association can work though a reduction of the impact of one source of macroeconomic volatility - political frictions.

\section{The Model}

Consider the infinitely-lived economy inhabited by two types of households: type $i$ and type $j$, where the type defines the relative household preferences for public versus private consumption. There are also two parties representing each type of household and competing for the seats in the government. The government is run by the party that wins the elections; the party that loses the elections stays in opposition. The government sets the levels of two types of government spending, $g$ and $x$.

The economy resource constraint is as follows:

$$
c+g+x=l,
$$

where $l$ denotes labor hours, and $c$ denotes private consumption.

We assume that the government spending $g$ delivers utility to the households, while the government spending $x$ does not deliver utility to the household but is valued by the government. We refer to $g$ and to $x$ as mandatory and discretionary government spending, respectively. Households of type $i$ place weight $\lambda_{i}$ on the utility derived from the public sector consumption $g$ while households of type $j$ place weight $\lambda_{j}$ on the utility from public consumption $g$. 
The instantaneous utility function of the household of type $h$ is given by:

$$
U(h, c, l, g)=\left(1-\lambda_{h}\right) \log \left(c-\frac{1}{\varphi} \frac{l^{1+\frac{1}{\epsilon}}}{1+\frac{1}{\epsilon}}\right)+\lambda_{h} \log (g), h \in\{i, j\} .
$$

The households work $l$ hours in competitive firms for wage normalized to one. The government finances public expenditures through the proportional income tax $\tau$. The household budget constraint reads:

$$
c=(1-\tau) l
$$

The households maximize their utility subject to their budget constraint. The solution to the household maximization problem is independent of the household type and sets the optimal labor and consumption as functions of government policy. We denote these functions as $\mathcal{L}(\tau)$ and $\mathcal{C}(\tau)$, respectively:

$$
\begin{aligned}
& \mathcal{L}(\tau):=\varphi^{\epsilon}(1-\tau)^{\epsilon} \\
& \mathcal{C}(\tau):=\varphi^{\epsilon}(1-\tau)^{1+\epsilon}
\end{aligned}
$$

We can define the competitive equilibrium in this economy as follows.

Competitive Equilibrium: given the government policy, the households maximize their utility (2) subject to their budget constraint (3), and the resource constraint (1) holds.

Next, we characterize the government policy.

The government is run by one of the two parties, each representing its household type: $i$ or $j$. Each party wins the election with probability driven by the transition matrix $[p 1-p ; 1-p p]$, where $p$ is the probability of winning, conditional of being in power during the last period. We refer to the difference between $\lambda_{i}$ and $\lambda_{j}$ as political polarization and to $p$ as the measure of political instability. ${ }^{2}$

The instantaneous utility function of the party of type $h$ combines the utility of its electorate plus the utility (assumed to be linear with weight $\theta>0$ ) from discretionary public spending $x$ :

$$
u(h, c, l, g, x)=\left(1-\lambda_{h}\right) \log \left(c-\frac{1}{\varphi} \frac{l^{1+\frac{1}{\epsilon}}}{1+\frac{1}{\epsilon}}\right)+\lambda_{h} \log (g)+\theta x, h \in\{i, j\} .
$$

\footnotetext{
${ }^{2}$ Azzimonti (2011) endogenizes the probability $p$ in a voting model in which the outcome of the election is dictated by political preference shock as well as voters' expectations about the economic outcomes. Here we assume that both political instability $p$ and political polarization $\lambda_{j}-\lambda_{i}$ are exogenous.
} 
The party which loses the elections stays in opposition and can influence the government policy by supporting or rejecting the party's in power fiscal plan. Similar to the party in power, the opposition party enjoys utility from $x$.

The government budget constraint is as follows:

$$
g+x=\tau l
$$

We model mandatory spending as in Bowen, Chen and Eraslan (2014). The party in power chooses the current public spending, $g$ and $x$, subject to the approval by the opposition (the party which lost the elections). ${ }^{3}$ The opposition approves the incumbent policy if its utility from that policy is greater than that under the status quo. The status quo consists of the previous period level of mandatory spending, $s$, and zero discretionary spending.

We assume that the government is benevolent with respect to its electorate, but extremely impatient and thus consider its discount factor to be zero. This assumption simplifies the government problem significantly without affecting our main results (for a range of discount factors). We discuss the role of the government impatience and different discount factors in Section 5 of this paper.

Given the extreme impatience assumption, the government only takes into account the current period utility when choosing its policy and its maximization problem does not depend on future policies. In particular, if the party $i$ is currently in power, its optimization problem is as follows:

$$
\begin{aligned}
& \max _{g, \tau} u(i, \mathcal{C}(\tau), \mathcal{L}(\tau), g, \tau \mathcal{L}(\tau)-g) \\
& \text { s.t. : } u(j, \mathcal{C}(\tau), \mathcal{L}(\tau),(\tau), g, \tau \mathcal{L}(\tau)-g) \geq u\left(j, \mathcal{C}\left(\tau_{s}\right), \mathcal{L}\left(\tau_{s}\right), s, 0\right),
\end{aligned}
$$

where $x$ has been substituted away using (7) and $\tau_{s}$ is the tax rate under the status quo policy $(g=s$ and $x=0)$, and can be calculated from the government budget constraint (7) which reads:

$$
\tau_{s}\left(1-\tau_{s}\right)^{\epsilon} \varphi^{\epsilon}=s .
$$

\footnotetext{
${ }^{3}$ Thus, we consider a political system with unanimity rule. As in Bowen, Chen and Eraslan (2014), we justify this assumption by the fact that many political systems have institutions that limit a single party's power, for example, the "checks and balances" included in the U.S. Constitution. Under these institutions, if the majority party's power is not suffciently high, then it needs approval of the other party to set new policies (Bowen, Chen and Eraslan, 2014).
} 
We assume that the opposition party always accept the policy suggested by the party in power if it is indifferent between acceptance and rejection. Then, in equilibrium all the proposals are accepted.

Given that the parties competing for public office have different preferences regarding fiscal policy, the economy is characterized by fluctuations due to two frictions: political polarization and political turnover, even in the absence of any other sources of economic volatility. We aim to show that introducing stronger government institutions in the form of the status quo constraint (9) can reduce the impact of political frictions on macroeconomic volatility. We discuss the role of other sources of fluctuations in Section 5 of this paper.

We assume that the parameter values are such that the optimal tax rates are not too high:

Assumption 1: $\tau<\frac{2}{1+\epsilon}$.

This assumption is innocuous given that the empirical estimates of labor elasticity $\epsilon$ lie around 1.7, while empirical tax rates do not exceed $60 \%$.

Next, we briefly characterize the role of mandatory public spending enabled by the status quo constraint (9) for macroeconomic volatility with the help of two propositions below. In the next section, we refer to numerical simulations to evaluate the quantitative effect of mandatory spending on politically-driven economic volatility.

Proposition 1: Introducing mandatory spending reduces economic volatility.

(Proof is in the Appendix).

Proposition 2: In the economy with the binding status quo constraint, keeping the tax rate constant, higher fraction of mandatory spending in total government spending leads to lower economic volatility.

(Proof is in the Appendix).

Importantly, Propositions 1 and 2 hold when the status quo constraint is at least occasionally binding. This happens when the fraction of mandatory spending in total government spending is large enough. Thus, the status quo constraint reduces the impact of political frictions on economic volatility for the fractions of mandatory spending in total public spending above a certain threshold, consistent with the empirical results outlined in Table 1. 
Note that in any given period in the economy with the status quo constraint of the form (9), the policy choices are Pareto optimal from the point of view of the parties competing for power: the chosen policies maximize the utility of the party in power subject to the reservation utility of the party out of power given by the status quo $s$. However, the role of mandatory spending for household welfare is ambiguous because the changes in the composition of government spending lead to the changes in the weights on different components of the household utility function.

In the next section, we solve the model with the help of numerical simulations to quantify the effect of political frictions, mandatory spending, and their interplay on macroeconomic volatility.

\section{Numerical Simulations of the Model}

This section provides a quantitative analysis of the model outlined in the previous section. We choose to calibrate the model to the U.S. economy, given that it has the most complete data on mandatory spending, discretionary spending, and political polarization over time. Moreover, the pattern of U.S. time series (as depicted in Figure 1) provides an ideal environment for the evaluation of mandatory spending and political polarization contribution to macroeconomic volatility; there is a clear separation of the data into two sub-periods with relatively high fraction of discretionary spending in the first sub-period and relatively high fraction of mandatory spending in the second sub-period. At the same time, the total government spending share of output (not shown on the graph) is relatively constant across the two sub-periods.

Thus, for the calibration, we split the entire time series into two sub-periods: the first one from 1962 to 1984, and the second one from 1985 to 2015. The second sub-period coincides with the "Great Moderation" - a well-documented decrease in macroeconomic volatility. The rows named "Data" in Table 3 provide summary statistics for the two sub-periods. The data suggests that the average fraction of mandatory spending in total government spending increased from 0.40 to 0.58 and output volatility (multiplied by 100) decreased from 2.41 to 1.78 when we compare the two sub-periods. At the same time, the average total government spending as a fraction of output is the same in two periods, accounting for $18 \%$ of the GDP. 
Table 2: Parameters and values.

\begin{tabular}{lccl} 
Parameter & Notation & Value & Target \\
& & & \\
\hline Avg weight on mandatory spend. & $\bar{\lambda}$ & 0.28 & $\operatorname{mean}\left(\frac{g+x}{y}\right)$ \\
Political polarization & $d \lambda$ & 0.13 & $\operatorname{mean}\left(\frac{g}{g+x}\right)$ \\
Weight on discretionary spend. & $\theta$ & 3.77 & $\operatorname{sd}(y)$ \\
Elasticity of labor & $\epsilon$ & 1.70 & Literature \\
Utility weight on labor & $\varphi$ & 1.22 & mean $(y)=1$ \\
Prob. of re-election & $p$ & 0.90 & Literature \\
\hline
\end{tabular}

We calibrate three key model parameters to match three moments from the first subperiod. In particular, we choose the average economy-wide weight on the utility from mandatory spending $\bar{\lambda}=\frac{\lambda_{i}+\lambda_{j}}{2}$, the political polarization $d \lambda=\lambda_{j}-\bar{\lambda}=\bar{\lambda}-\lambda_{i}$, and the weight on discretionary spending $\theta$ to replicate the average total government spending as a fraction of output, mean $\left(\frac{g+x}{y}\right)=\tau$, the average fraction of mandatory spending in total government spending, mean $\left(\frac{g}{g+x}\right)$, and the standard deviation of output, $s d(y)$, in the U.S. over 1962-1985. We use the standard value for the elasticity of labor $\epsilon=1.7$ and we choose $\varphi$ so that the average output in the calibrated economy is equal to one. The probability of re-election, conditional on being in power in the previous period, $p$ does not affect the government maximization problem but determines the magnitude of fluctuations in the economy. We set $p=0.9$, the value that has been used as the probability of re-election for the U.S. economy (see Ilzetski, 2011). We denote the calibrated model as Model(0). Table 2 summarizes the parameter values.

Figure 3 shows how three key calibrated parameters affect the moments of interest, other things being equal. The top panel reports the average tax rate (equal to the total government spending as a fraction of output), the average mandatory spending as a fraction of total government spending, and the standard deviation of output, as functions of $d \lambda, \bar{\lambda}$, and $\theta$ in the model economy without the status quo constraint. The bottom panel shows the same statistics for the economy with the occasionally binding status quo constraint. Each graph is constructed by increasing one of the three parameters $(d \lambda, \bar{\lambda}$, or $\theta)$ and keeping the other two parameters constant. The results suggest that the economy without the status quo constraint is characterized by higher average taxes and higher output volatility, consistent with Proposition 1. Higher political polarization $d \lambda$ decreases taxes, 
the fraction of mandatory spending, and output volatility in the economy with the status quo constraint, and increases taxes and macroeconomic volatility in the economy without status quo constraint. Higher weight on discretionary government spending $\theta$ increases (decreases) the output volatility in the economy with (without) the status quo constraint, consistent with Proposition 2.

Figure 3: The effect of the model parameters on the moments of interest.
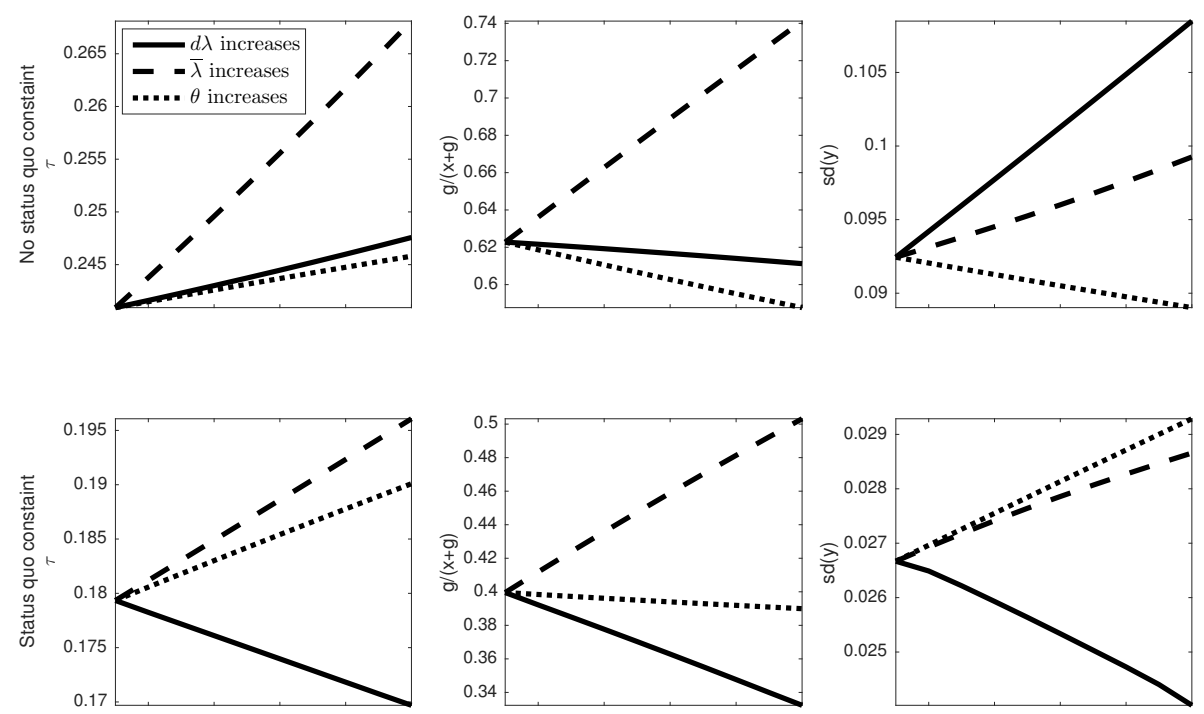

The graphs in the first row show the impact of the parameter values on the average tax rate $\tau$, average $g / G$, and the standard deviation of $y$ for the economy without the status quo constraint; the graphs in the second row show the same statistics for the economy with (occasionally) binding status quo constraint. Each line is obtained by changing one parameter keeping the other parameters constant at their values listed in Table 3 .

Next, we conduct three experiments:

- $[\operatorname{Model}(1):]$ First, we reduce the parameter $\theta$ so that the average fraction of mandatory spending in total government spending matches the increase observed in the data: 0.58 . In this way, we account for the sole impact of higher mandatory and lower discretionary spending on macroeconomic volatility.

- $[\operatorname{Model}(2):]$ Second, we reduce the parameter $\theta$ adjusting $\bar{\lambda}$ so that the average government spending fraction of output stays constant and equal to 0.18 , and the average 
Table 3: Data and Model

\begin{tabular}{llccc}
\hline Time period & Data/Model & mean $\left(\frac{g+x}{y}\right)$ & mean $\left(\frac{g}{g+x}\right)$ & $s d(y)$ \\
\hline \multirow{2}{*}{$1962-1984$} & Data & $\mathbf{0 . 1 8}$ & $\mathbf{0 . 4 0}$ & $\mathbf{2 . 4 1}$ \\
& Model(0) & 0.18 & 0.40 & 2.41 \\
& & & & \\
& Data & $\mathbf{0 . 1 8}$ & $\mathbf{0 . 5 8}$ & 1.78 \\
& Model(1) $\theta \downarrow$ & 0.12 & 0.58 & 1.06 \\
& $\operatorname{Model}(2) \theta \downarrow, \bar{\lambda} \uparrow$ & 0.18 & 0.58 & 6.29 \\
& $\operatorname{Model}(3) \theta \downarrow, \bar{\lambda} \uparrow, d \lambda \uparrow$ & 0.18 & 0.58 & 2.11 \\
\hline
\end{tabular}

For the calculation of the standard deviation the variables are de-trended using HP-filter with smoothing coefficient 100. De-trending using HP-filter with coefficient 6.25 or differences of logarithms gives similar results. Targeted moments in bold.

fraction of mandatory spending in total government spending increases to 0.58 . In this way, we account for the impact of mandatory spending on macroeconomic volatility while keeping the total government spending share of output constant, as in the data.

- $[\operatorname{Model}(3):]$ Finally, we simultaneously reduce the parameter $\theta$ and increase political polarization $d \lambda$, adjusting $\bar{\lambda}$ to keep the average government spending fraction of output constant and equal to 0.18 and to increase the average fraction of mandatory spending in total government spending to 0.58 . In this way, we account for the joint effect of mandatory spending and political polarization on macroeconomic volatility.

For each experiment, we simulate the model economy 300 times for 30 periods - the length of the period considered in the data - and report the average statistics. Table 3 presents the results. ${ }^{4}$

Increasing the share of mandatory spending in total government spending by reducing the weight on discretionary spending $\theta$ leads to a significant decline in the output volatility (by more than twice compared with the first sub-period). At the same time, the rela-

\footnotetext{
${ }^{4}$ We do not evaluate the sole impact of political polarization because changing only $d \lambda$ (in either direction) results in the targeted moments, the share of total government spending in output and the share of mandatory spending in total government spending, being diverging significantly from the data (this can be observed from Figure 3). The political polarization alone cannot explain the patterns observed in the data.
} 
tive weight on the utility from private consumption increases so that the share of total government spending in total output is now much lower at only twelve percent.

Given that the data shows the average share of total government spending in total output remaining the same during both sub-periods, in the second experiment, we increase the average economy-wide weight on mandatory spending $\bar{\lambda}$, reducing $\theta$ at the same time. It this way, we match both the fraction of mandatory spending in total government spending and the fraction of total government spending in output observed during the second subperiod. However, the output volatility generated by the model is two and a half times higher than the volatility observed in the first sub-period.

Finally, we allow all three key parameters to change. This generates a fraction of mandatory spending in total government spending, and the fraction of total government spending in output observed in the data and output volatility, which is $12 \%$ lower than in the first sub-period. The output volatility observed in the second sub-period in the data is $26 \%$ lower than in the first sub-period. Thus, varying the three key parameters of the model in the direction consistent with their changes in the data allows us to account for around $50 \%$ of the total decline in output volatility in the U.S. between 1962-1984 and 1985-2015.

In this numerical exercises, we do not account for any other sources of macroeconomic volatility, such as exogenous technology shocks. Adding exogenous shocks leads to economic fluctuations of a different nature compared to the politically-driven fluctuations considered so far. The mandatory spending institution is efficient in smoothing volatility from political frictions but can be detrimental in the case of volatility caused by technological shocks. The latter volatility is better smoothed if the government has sufficient freedom to vary its discretionary spending (Fatás and Mihov 2003, 2006). In the next section, we consider the impact of exogenous technology shocks and the role of government impatience for the model performance, as well as discuss the importance of the government size.

\section{Discussion and Extensions}

In this section, we consider several extensions of the basic model analyzed in the previous sections, and we discuss the potential role of government size. 


\subsection{The Role of Exogenous Technology Shocks}

The only source of volatility we have considered so far is political disagreement about the size and composition of the public sector combined with political turnover. We have shown that the institution that introduces mandatory public spending can reduce these politically driven fluctuations. However, there are many other potential sources of economic fluctuations: technology shocks, terms of trade shocks, sudden changes in taste and preferences, etc. The justification behind the use of discretionary fiscal policy is that, by changing the level of discretionary spending quickly and easily, the government can reduce the negative impact of such exogenous shocks on economic variables. Thus, there is a trade-off between the fraction of mandatory spending useful for reduction of the political frictions consequences and the fraction of discretionary spending useful for reduction of exogenous shocks not caused by governmental inefficiencies.

To check how our model behaves in the environment with exogenous economic shocks, we add fluctuations in labor productivity or technology. For this purpose, we introduce a new variable, $z$, which measures labor productivity, so that the economy technology constraint (1) now reads:

$$
c+g+x=z l .
$$

Following the literature on the real business cycles, we assume that the logarithm of $z$ follows an $\mathrm{AR}(1)$ process as follows:

$$
\log \left(z_{t}\right)=\rho \log \left(z_{t-1}\right)+\sigma e_{t}
$$

where $e_{1} \backsim N(0,1)$.

We simulate the models replicating the two sub-periods of U.S. data considered in the previous section-Model(0) and $\operatorname{Model}(3)-$ for the economy with $z$. For the simulations, we use standard empirical estimates of the stochastic process for $z: \rho=0.81$ and $\sigma=0.0144$ (Ilzetski, 2011). The simulated models still replicate well the two targeted moments: the fraction of total government spending in output and the fraction of mandatory spending in the total government spending. However, the resulting output volatilities are much higher. The output volatility for $\operatorname{Model}(0)$ is 3.52 and the output volatility for $\operatorname{Model}(3)$ is 4.75. That is, the macroeconomic volatility increases as we increase the fraction of mandatory spending and political polarization. This result is in contrast to the one we obtained in the previous section where $\operatorname{Model}(3)$ generated lower output volatility compared 
with Model(0). Thus, our model augmented by exogenous technology shocks exhibits the trade-off between mandatory and discretionary spending similar to the one discussed in the empirical literature (Fatás and Mihov 2003, 2006): By increasing the fraction of mandatory spending, we reduce the government's ability to smooth fluctuations caused by exogenous shocks unrelated to political frictions.

This result implies that further research is needed regarding the relative importance of different sources of economic fluctuations and the optimal composition of government spending. Answering these questions would require taking into account a number of country-specific characteristics, including population structure, income distribution, its stage of economic development, its degree of openness, and other factors that can potentially influence the responsiveness of the economy to exogenous shocks, besides the political frictions.

\subsection{The Role of Government Impatience}

In the model considered so far, we assumed that the government was extremely impatient, characterized by zero discount factor. In this way, we removed the link between current and future policies and significantly simplified the model. Here we relax this assumption to show that the government impatience is not crucial for the main properties of the model for a range of discount factors.

Consider the government with a discount factor $\beta>0$. In this case, the government problem modifies as follows (we assume that party $i$ is in power):

$$
\begin{aligned}
& \max _{g, \tau} u(i, \mathcal{C}(\tau), \mathcal{L}(\tau), g, \tau \mathcal{L}(\tau)-g)+\beta\left(p V_{i}\left(s^{\prime}\right)+(1-p) W_{i}\left(s^{\prime}\right)\right) \\
& \text { s.t. }: u(j, \mathcal{C}(\tau), \mathcal{L}(\tau),(\tau), g, \tau \mathcal{L}(\tau)-g)+\beta\left((1-p) V_{j}\left(s^{\prime}\right)+p W_{j}\left(s^{\prime}\right)\right) \geq \\
& u\left(j, \mathcal{C}\left(\tau_{s}\right), \mathcal{L}\left(\tau_{s}\right), s, 0\right)+\beta\left((1-p) V_{j}(s)+p W_{j}(s)\right),
\end{aligned}
$$

where $V_{h}$ and $W_{h}, h \in i, j$ denote the value functions of the party in power and the party out of power, respectively.

We consider the Markov-perfect equilibrium where the parties strategies depend only on the pay-off relevant state - the status quo $s$ in this case. We assume that the opposition party always accept the policy suggested by the party in power if it is indifferent between acceptance and rejection. Then, in equilibrium all the proposals are accepted. The political 
equilibrium is defined in the appendix.

In this setup, the party which is currently in power takes into account the impact of its policy choice on its utility in the future. Moreover, both the party in power and the opposition party take into account political turnover by accounting for the probability that they will remain in their current roles in the following period.

Figure 4: Policy functions.
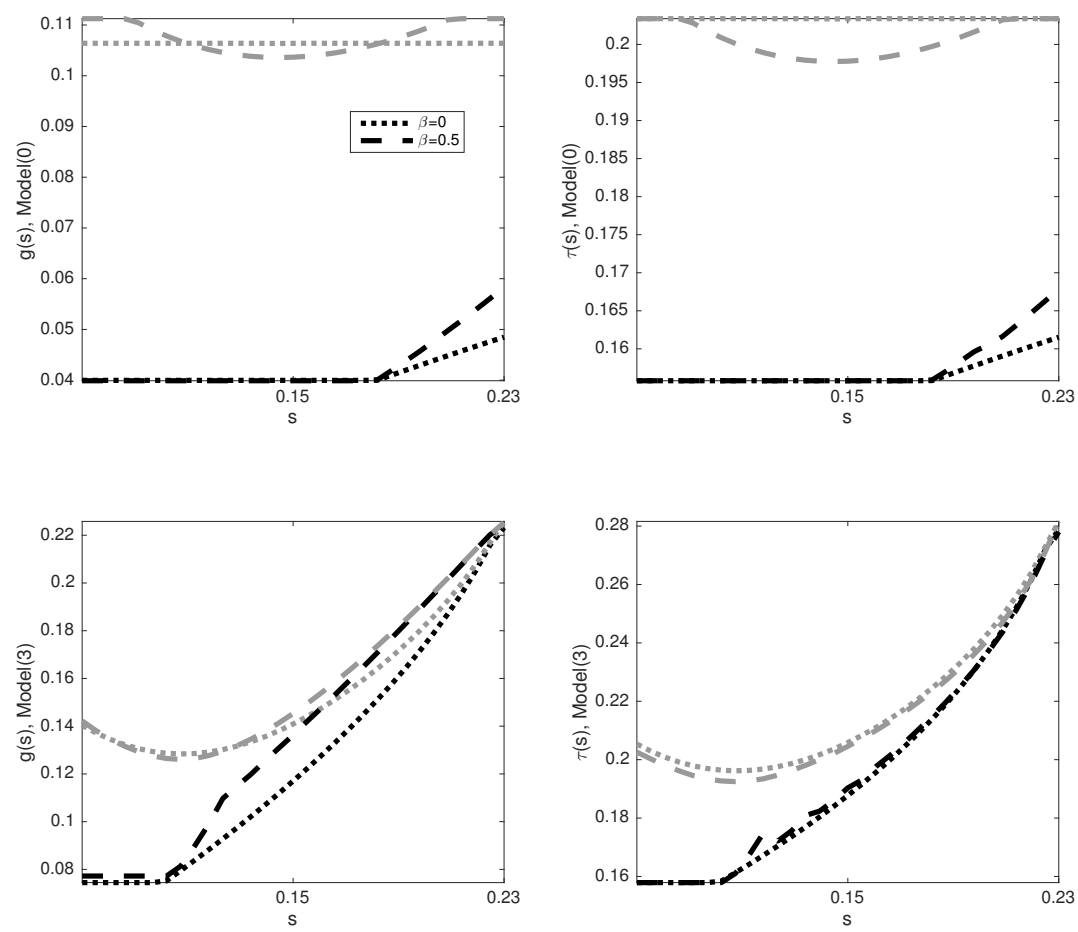

The figures show the policy functions $g(s)$ and $\tau(s)$ on the right and left panel, respectively, for the parameter values used for $\operatorname{Model}(0)$ and $\operatorname{Model}(3)$ on the top and bottom panels, respectively. The dotted line corresponds to the economy with $\beta=0$; the dashed line corresponds to the economy with $\beta=0.5$. The policies chosen by party $i$ and $j$ are in black and grey, respectively.

We numerically approximate the solution to the equilibrium of this extended model. We try a number of values for the government discount factor in a range $\beta \in[0 ; 96]$ and a number of values for the political turnover $p \in[0.5 ; 0.9]$. For the relatively low discount factors and/or political turnover levels (e.g., $\beta \leq 0.8$ or $p \simeq 0.5$ ), the approximated solutions are close to the solutions of the static model characterized by $\beta=0 .{ }^{5}$

\footnotetext{
${ }^{5}$ For the large discount factors $(\beta>0.8)$ and/or large probabilities of re-election $p$, the model does not converge to any stationary equilibrium.
} 
Figure 4 presents the policy functions (optimal mandatory spending and optimal tax rate for party $i$ and for party $j$ as functions of the status quo $s$ ) for the case when $\beta=0.5$ and $p=0.9$ (dynamic model) together with the corresponding policy functions for the model economy where the government discount factor is zero (static model). The results suggest that policy functions are slightly more responsive in the dynamic model, as tax and government spending change by a larger amount. However, the direction and the shape of the policy function's responses to the binding status-quo constraint are not affected compared to the static model. The simulations of the dynamic model economy result in the moments very similar to those reported in Table 3.

Relatively low patience of politicians compared to citizens have been used in the political economy literature (see Acemoglu et al. 2008a, 2008b, 2011a, 2011b) and is usually justified by the fact that politicians do not hold office indefinitely. The question of an empirically relevant government discount factor remains a topic requiring further research.

\subsection{The Role of the Government Size}

The size of the government sector can influence economic growth and volatility (see Fatás and Mihov, 2001; Andrés, Doménech, and Fatás, 2008.; Afonso and Furceri, 2010). In the calibration considered in previous sections, we fixed the government size because the data suggests that it was relatively constant during the time period under study. The question of the optimal government size requires a separate, careful investigation. Too large a public sector can be detrimental to economic growth, because it restricts private investment. Too small a public sector can also have negative consequences for the economy, if the size restriction result in under-provision of necessary public goods.

In this sense, the mandatory spending institutions discussed in this paper can have consequences beyond political fluctuations smoothing. If the public sector is too large, a higher fraction of mandatory spending implies that the public sector is more rigid to modifications so that growth-enhancing reforms can be more difficult to implement. Brazil is an example of a country characterized by a large and rigid public sector due to a high fraction of mandatory spending, close to 100\% (Celasun et. al, 2015). Besides a high tax burden, these rigidities make it difficult to adapt public expenditure to changing realities and priorities (OECD, 2015). We leave for further research the questions of the optimal size of the government sector and of mandatory spending in particular, given the state of 
political institutions and the stage of economic development.

\section{Conclusions}

In this paper, we have discussed a fiscal policy institution that can reduce the impact of political frictions on economic volatility. We have shown that, given government size, both introducing and increasing the fraction of mandatory spending leads to lower fluctuations caused by political disagreement and political turnover. Our findings emphasize the importance of fiscal rules for both developing and developed countries.

The research conducted in this paper can be extended in several directions. First, one could analyze the optimal fraction of mandatory spending given the state of political institutions and economic development. Second, the relative importance of discretionary and mandatory spending could be quantified for particular economies, given their characteristics. For that purpose, it would be necessary to disentangle the fluctuations caused by purely political reasons from the fluctuations caused by the shocks unrelated to political frictions. Finally, one can explore the more complicated question of how to facilitate the introduction and functioning of strong fiscal institutions in the economies that currently lack them.

\section{References}

1. Acemoglu, D., Johnson, S., Robinson, J. and Thaicharoen, Y., 2003. Institutional causes, macroeconomic symptoms: volatility, crises and growth. Journal of monetary economics, 50(1), pp.49-123.

2. Acemoglu, D., Golosov, M., Tsyvinski, A., 2008a. Markets versus governments. Journal of Monetary Economics 55(1), 159-189.

3. Acemoglu, D., Golosov, M., Tsyvinski, A., 2008b, Political economy of mechanisms. Econometrica 76(3), 619-641.

4. Acemoglu, D., Golosov, 'm., Tsyvinski, A., 2011a. Political economy of Ramsey taxation. Journal of Public Economics 95(7), 467-475.

5. Acemoglu, D., Golosov, M., Tsyvinski, A., 2011b. Power fluctuations and political economy. Journal of Economic Theory 146(3), 1009-1041. 
6. Adema, W., P. Fron and M. Ladaique 2011. Is the European Welfare State Really More Expensive? Indicators on Social Spending, 1980-2012; and a Manual to the OECD Social Expenditure Database (SOCX), OECD Social, Employment and Migration Working Papers No. 124

7. Afonso, A. and Furceri, D., 2010. Government size, composition, volatility and economic growth. European Journal of Political Economy, 26(4), pp.517-532.

8. Alesina, A., F. R. Campante, and G. Tabellini. 2008. Why is fiscal policy often procyclical? Journal of the European Economic Association 6(5): 1006-1036.

9. Alesina, A. and Tabellini, G., 1990. A positive theory of fiscal deficits and government debt. The Review of Economic Studies, 57(3), pp.403-414.

10. Andrés, J., R. Doménech, and A. Fatás., 2008. The stabilizing role of government size. Journal of Economic Dynamics and Control 32(2): 571-593.

11. Azzimonti, M., 2011. Barriers to investment in polarized societies. The American Economic Review, 101(5), pp.2182-2204.

12. Azzimonti, M. and Talbert, M., 2014. Polarized business cycles. Journal of Monetary Economics, 67, pp.47-61.

13. Battaglini, M., and St. Coate. 2008. A Dynamic Theory of Public Spending, Taxation and Debt. American Economic Review, 98(1): 201-236.

14. Bowen, T.R., Chen, Y. and Eraslan, H., 2014. Mandatory versus discretionary spending: The status quo effect. The American Economic Review, 104(10), pp.2941-2974.

15. Celasun, O., Grigoli, F., Honjo, M.K., Kapsoli, M.J., Klemm, M.A., Lissovolik, M.B., Luksic, J., Badia, M.M.M., Pereira, M.J., Poplawski-Ribeiro, M. and Shang, B., 2015. Fiscal policy in Latin America: Lessons and legacies of the global financial crisis (No. 15-16). International Monetary Fund.

16. Esteban, J. and Ray, D., 2011. Linking conflict to inequality and polarization. The American Economic Review, 101(4), pp.1345-1374.

17. Fatás, A. and Mihov, I., 2001. Government size and automatic stabilizers: international and intranational evidence. Journal of International Economics, 55(1), pp.3-28. 
18. Fatás, A. and Mihov, I., 2003. The Case for Restricting Fiscal Policy Discretion. The Quarterly Journal of Economics, 118(4), pp.1419-1447.

19. Fatás, A. and Mihov, I., 2006. The macroeconomic effects of fiscal rules in the US states. Journal of public economics, 90(1), pp.101-117.

20. Fatás, A. and Mihov, I., 2013. Policy volatility, institutions, and economic growth. Review of Economics and Statistics, 95(2), pp.362-376.

21. Ilzetzki E. 2011. Rent-seeking distortions and fiscal procyclicality. Journal of Development Economics 96 (1): 30-46.

22. Klomp, J. and de Haan, J., 2009. Political institutions and economic volatility. European Journal of Political Economy, 25(3), pp.311-326.

23. OECD, 2015. OECD Better Policies Series: Brazil Policy Brief. forthcoming.

24. Persson, T., and L.E.O. Svensson. 1989. Why a Stubborn Conservative Would Run a Deficit: Policy with Time-Inconsistent Preferences. Quarterly Journal of Economics, 104(2): 325-345.

25. Persson, T., and G. Tabellini. 2000. Political Economics: Explaining Economic Policy. MIT Press.

26. Poole, K. T. and H. Rosenthal (2000). Congress: A Political-Economic History of Roll Call Voting. Oxford University Press.

27. Tornell, Aaron, and Philip R. Lane. 1999. The voracity effect. American Economic Review. 22-46.

28. Woo, J., 2009. Why do more polarized countries run more procyclical fiscal policy?. The Review of Economics and Statistics, 91(4), pp.850-870.

29. Yared, P., 2010. Politicians, taxes and debt. The Review of Economic Studies, 77(2), pp. $806-840$. 


\section{Appendix}

\section{Government problem optimality conditions}

Substituting the optimal consumption and labor functions, $\mathcal{C}(\tau)$ and $\mathcal{L}(\tau)$, into the government utility and simplifying, the government problem (8)-(9) reads as follows:

$$
\begin{aligned}
& \max _{g, \tau}\left(1-\lambda_{i}\right) \log \left(\frac{(1-\tau)^{1+\epsilon} \varphi^{\epsilon}}{1+\epsilon}\right)+\lambda_{i} \log (g)+\theta\left(\tau(1-\tau)^{\epsilon} \varphi^{\epsilon}-g\right) \\
& \text { s.t. : }\left(1-\lambda_{j}\right) \log \left(\frac{(1-\tau)^{1+\epsilon} \varphi^{\epsilon}}{1+\epsilon}\right)+\lambda_{j} \log (g)+\theta\left(\tau(1-\tau)^{\epsilon} \varphi^{\epsilon}-g\right) \geq \\
& \left(1-\lambda_{j}\right) \log \left(\frac{\left(1-\tau_{s}\right)^{1+\epsilon} \varphi^{\epsilon}}{1+\epsilon}\right)+\lambda_{j} \log (s),
\end{aligned}
$$

where $\tau_{s}$ is given by $\tau_{s}\left(1-\tau_{s}\right)^{\epsilon} \varphi^{\epsilon}=s$.

The first-order conditions to the government problem are the following:

$$
\begin{aligned}
& -\frac{1+\epsilon}{1-\tau}\left(1-\lambda_{i}+\mu\left(1-\lambda_{j}\right)\right)+\theta \varphi^{\epsilon}\left((1-\tau)^{\epsilon}-\epsilon \tau(1-\tau)^{\epsilon-1}\right)(1+\mu)=0, \\
& \frac{1}{g}\left(\lambda_{i}+\mu \lambda_{j}\right)-\theta(1+\mu)=0, \\
& \mu\left[\left(1-\lambda_{j}\right) \log \left(\frac{(1-\tau)^{1+\epsilon} \varphi^{\epsilon}}{1+\epsilon}\right)+\lambda_{j} \log (g)+\theta\left(\tau(1-\tau)^{\epsilon} \varphi^{\epsilon}-g\right)-\right. \\
& \left.\left(1-\lambda_{j}\right) \log \left(\frac{\left(1-\tau_{s}\right)^{1+\epsilon} \varphi^{\epsilon}}{1+\epsilon}\right)-\lambda_{j} \log (s)\right]=0,
\end{aligned}
$$

where $\mu$ is a multiplier on the constraint (16).

\section{Proof of Proposition 1}

Proof. Assume without loss of generality that $\lambda_{i}<\lambda_{j}$. We compare the economies without and with the constraint (9) incorporating status quo mandatory spending. Without the status quo constraint, the multiplier $\mu$ in the first order conditions (17)-(18) is always zero. Thus, the optimal policy choice by the party $\lambda_{i}$ when in power is $g_{i}^{\star}=\frac{\lambda_{i}}{\theta}$ and $\tau_{i}^{\star}$ defined by the implicit function $u_{\tau}\left(\tau_{i}^{\star}, \lambda_{i}\right)$ as follows:

$$
u_{\tau}\left(\tau_{i}^{\star}, \lambda_{i}\right)=-\frac{1+\epsilon}{1-\tau_{i}^{\star}}\left(1-\lambda_{i}\right)+\theta \varphi^{\epsilon}\left(\left(1-\tau_{i}^{\star}\right)^{\epsilon}-\epsilon \tau_{i}^{\star}\left(1-\tau_{i}^{\star}\right)^{\epsilon-1}\right)=0 .
$$

Applying the Implicit function theorem, we obtain that

$$
\frac{d \tau_{i}^{\star}}{d \lambda_{i}}=-\frac{u_{\tau \lambda_{i}}\left(\tau_{i}^{\star}, \lambda_{i}\right)}{u_{\tau \tau}\left(\tau_{i}^{\star}, \lambda_{i}\right)}=-\frac{\frac{1+\epsilon}{1-\tau_{i}^{\star}}}{u_{\tau \tau}\left(\tau_{i}^{\star}, \lambda_{i}\right)}>0,
$$


because

$$
u_{\tau \tau}\left(\tau, \lambda_{i}\right)=-\frac{(1+\epsilon)\left(1-\lambda_{i}\right)}{(1-\tau)^{2}}+\theta \varphi^{\epsilon} \epsilon(1-\tau)^{\epsilon-1}\left(-2+(\epsilon-1) \frac{\tau}{(1-\tau)}\right)<0
$$

that is, the utility function is strictly concave in $\tau$.

Consider now the economy with the (at least occasionally binding) status quo constraint and assume (without loss of generality) that party $i$ is in power. The status quo $s$ is binding when

$$
u\left(\tau_{i}^{\star}, \lambda_{j}\right) \leq u\left(\tau_{s}, \lambda_{j}\right)
$$

where $t_{s}\left(1-t_{s}\right)^{\epsilon} \varphi^{\epsilon}=s$. Given concavity of $u$, there are maximum two possible status quo states in between which the constraint is binding. Denote these states by $s_{\min }$ and $s_{\max }$ and the associated with them tax rates $\tau_{s}\left(s_{\min }\right)$ and $\tau_{s}\left(s_{\max }\right)$. Given the concavity of $u$ and the fact that $\tau$ is continuous and increasing in $\lambda$, the following inequalities hold:

$$
\begin{aligned}
& u\left(\tau\left(\lambda_{j}\right), \lambda_{i}\right)<u\left(\tau_{s}\left(s_{\min }<s<s_{\max }\right), \lambda_{i}\right)<u\left(\tau\left(\lambda_{i}\right), \lambda_{i}\right)=u\left(\tau_{i}^{\star}, \lambda_{i}\right), \\
& \tau\left(\lambda_{i}\right)<\tau_{s}\left(s_{\min }<s<s_{\max }\right)<\tau\left(\lambda_{j}\right) .
\end{aligned}
$$

Thus, the optimal policy for $i$ when the status quo constraint is binding is to choose $\bar{\tau}_{i} \in\left(\tau_{i}^{\star}, \tau_{s}\right]$.

Same logic applies when the party $j$ is in power. Its optimal strategy under binging status quo constraint is to choose $\bar{\tau}_{j} \in\left[\tau_{s}, \tau_{j}^{\star}\right)$. Given that the volatility of output, labour, consumption, and taxes in this economy is defined by the difference of the tax rates implemented by different parties in power, we conclude that the economy with the status quo constraint is less volatile that the economy without such constraint given that $\left|\bar{\tau}_{j}-\bar{\tau}_{i}\right|<\left|\tau_{j}^{\star}-\tau_{i}^{\star}\right|$

\section{Proof of Proposition 2}

Proof. Higher fraction of mandatory spending in total government spending keeping the tax rate constant implies that $\theta$ is lower. The mandatory spending status quo constraint (9) defines $\bar{\tau}_{i}$ or $\bar{\tau}_{j}$ as a function of status quo $s$. This constraint can be rewritten as follows (assuming party $i$ is in power):

$$
\left(\frac{1-\bar{\tau}_{i}}{1-\tau_{s}}\right)^{(1+\epsilon)\left(1-\lambda_{j}\right)}\left(\frac{g}{s}\right)^{\lambda_{j}} \geq e^{-\theta\left(\bar{\tau}_{i}\left(1-\bar{\tau}_{i}\right)^{\epsilon} \varphi^{\epsilon}-g\right)} .
$$


Lower $\theta$ implies that the right hand size of the above equation approaches 1 , and the relevant solution approaches $\tau_{s}$. Thus, for a given status quo, both parties choose the tax policy closer to $\tau_{s}$, which implies that economic fluctuations due to political uncertainty are reduced.

The definition of political equilibrium in the case of the government discount factor different from zero.

Political Equilibrium: An equilibrium satisfies

i. Given the value functions $\left\{V_{h}, W_{h}, V_{-h}, W_{-h}\right\} h \in\{i, j\}$, the party's $h$ policy functions $\left\{\mathcal{T}_{h}(s), \mathcal{G}_{h}(s)\right\}$ satisfy:

$$
\begin{aligned}
& \left\{\mathcal{T}_{h}(s), \mathcal{G}_{h}(s)\right\} \in \max _{g, \tau} u(h, \mathcal{C}(\tau), \mathcal{L}(\tau), g, \tau \mathcal{L}(\tau)-g)+\beta\left\{p V_{h}\left(s^{\prime}\right)+(1-p) W_{h}\left(s^{\prime}\right)\right\} \\
& \text { s.t. }: u(-h, \mathcal{C}(\tau), \mathcal{L}(\tau), g, \tau \mathcal{L}(\tau)-g)+\beta\left\{(1-p) V_{-h}\left(s^{\prime}\right)+p W_{-h}\left(s^{\prime}\right)\right\} \geq \\
& u\left(-h, \mathcal{C}\left(\tau_{s}\right), \mathcal{L}\left(\tau_{s}\right), s, 0\right)+\beta\left\{(1-p) V_{-h}(s)+p W_{-h}(s)\right\}, s^{\prime}=g, \tau_{s} A \mathcal{L}\left(\tau_{s}\right)=s
\end{aligned}
$$

ii. Given the policy functions $\left\{\mathcal{T}_{h}(s), \mathcal{G}_{h}(s), \mathcal{T}_{-h}(s), \mathcal{G}_{-h}(s)\right\}, h \in\{i, j\}$, the value functions $V_{h}, W_{h}, h \in\{i, j\}$ satisfy functional equations:

$$
\begin{aligned}
& V_{h}(s)=u\left(h, \mathcal{C}\left(\mathcal{T}_{h}(s)\right), \mathcal{L}\left(\mathcal{T}_{h}(s)\right), \mathcal{G}_{h}(s), \tau \mathcal{L}\left(\mathcal{T}_{h}(s)\right)-\mathcal{G}_{h}(s)\right)+ \\
& \beta\left\{p V_{h}\left(\mathcal{G}_{h}(s)\right)+(1-p) W_{h}\left(\mathcal{G}_{h}(s)\right)\right\} \\
& W_{h}(s)=u\left(h, \mathcal{C}\left(\mathcal{T}_{-h}(s)\right), \mathcal{L}\left(\mathcal{T}_{-h}(s)\right), \mathcal{G}_{-h}(s), \tau \mathcal{L}\left(\mathcal{T}_{-h}(s)\right)-\mathcal{G}_{-h}(s)\right)+ \\
& \beta\left\{(1-p) V_{h}\left(\mathcal{G}_{-h}(s)\right)+p W_{h}\left(\mathcal{G}_{-h}(s)\right)\right\} .
\end{aligned}
$$

